\title{
Guerra, sociedad y naturaleza humana en el pensamiento de Tucídides y los sofistas*
}

DOI: http://dx.doi.org/10.21830/19006586.183

Recibido: 3 de mayo de 2017 • Aceptado: 5 de junio de 2017

War, Society and Human Nature in Thucydides' Thought and the Sophists

Guerre, société et nature humaine dans la pensée de Thucydide et des sophistes

Guerra, sociedade e natureza humana no pensamento de Tucídides e os sofistas

H. Martín Alvarado ${ }^{a}$

* El artículo es el producto final que se presenta en el marco de un proyecto de investigación institucional, adelantado en la línea de "Sociología e Historia Militar", del grupo Posesmic, adscrito a la Facultad de Posgrados de la Escuela Militar "General José María Córdova”, cuya aprobación se hizo a comienzos del primer semestre del año 2017.

a Escuela Militar "General José María Córdova”, Bogotá, Colombia. Magíster en Filosofía, Universidad de los Andes, Bogotá, Colombia. <he50mar349@gmail.com>. 
Resumen. El objetivo de este artículo es contrastar los conceptos de sociedad y naturaleza humana en la obra de Tucídides con la doctrina antropológica del grupo de sofistas que fueron sus contemporáneos en el siglo V a. de C., tales como Protágoras, Trasímaco, Pródico, Critias y, en especial, Antifonte, maestro del historiador. No obstante, las ideas atribuidas a los representantes de este movimiento intelectual serán traídas a colación en torno a los detalles que Tucídides mismo extrajo de su descripción sobre la stásis o guerra civil en la ciudad de Corcira para dar cuenta de la invariabilidad del comportamiento humano en situaciones de necesidad extrema. En su narración de los hechos, Tucídides erige la stásis no solo como modelo de la Guerra del Peloponeso, sino que además la eleva al rango de paradigma universal de toda confrontación bélico-militar. En último análisis, y según el modo en que el caso es tratado por el autor en el libro III, 81-83, de su Historia, se verá que estos pasajes son además susceptibles de ser reinterpretados a la luz de las teorías sofísticas sobre los inicios de la civilización, las cuales sistematizan a su vez ideas subyacentes sobre la violencia y la constitución de las polis vigentes en ese momento. El tema sobre las relaciones entre el uso de la fuerza, la posibilidad del vínculo social y la naturaleza humana es aún hoy objeto de debate en el mundo académico de cara a los nuevos conflictos presentes en el escenario político internacional.

Palabras clave: guerra civil; naturaleza humana; sociedad; sofistas; stásis; Tucídides.

Abstract. The aim in this paper is to compare the concepts of society and human nature in Thucydides' work, with the anthropological doctrine from the group of sophists that were their contemporaries in the 5th century BC, such as Protagoras, Thrasymachus, Prodicus, Critias and, specially, Antiphon, the Greek historian's teacher. However, the ideas attributed to the representatives of this intellectual movement will be brought up regarding the details that Thucydides extracted from his own description of stásis or civil war in the city of Corcyra to give an account of the regularity of human behavior in a position of extreme necessity. In his account of events Thucydides himself set the stásis up not only as a model of the Peloponnesian War, he also raises it to the level of a universal paradigm of any military confrontation for war. In the final analysis, and according to the way in which the case is dealt with by the author in Book III, 81-83 of his History, we will see these passages can also be interpreted in the light of sophistic theories about the beginnings of civilization, and at the same time they systematize underlying ideas on violence and the constitution of the polis, ideas argued at that time. The subject of the relations among the use of force, the possibility of social ties and human nature is still the matter of debate in the academic world in the face of the new present conflicts in the international political atmosphere.

Keywords: civil war; human nature; society; sophists; stásis; Thucydides.

Résumé. Le but de cet article est de comparer les concepts de société et nature humaine dans l'œuvre de Thucydide, avec la doctrine anthropologique du groupe de sophistes qui furent ses contemporains au cinquième siècle avant Christ, comme par exemple Protagoras, Thrasymaque, Prodicos, Critias et, en particulier, Antiphon, maitre de l'historien. Cependant, les idées attribuées aux représentants de ce mouvement intellectuel pourraient être abordées autour des détails que Thucydide a lui-même tiré de sa description sur la stásis ou guerre civile dans la ville de Corcyre afin de rendre compte de l'invariabilité du comportement humain à l'abri des situations extrêmes. Dans son récit des faits, Thucydide a lui-même conçue la stásis non seulement comme modèle de la Guerre du Péloponnèse, mais avant tout comme l'émergence d'un paradigme universel pour toute confrontation militaire de guerre. En dernière analyse, et selon le mode retenu par l'auteur pour discuter du cas dans le livre III, 81-83 de son Histoire, nous pouvons constater que ces passages, en outre qu'ils sont susceptibles d'être réinterprétés à la lumière des théories des sophistes sur les débuts de la civilisation, que systématisent à son tour des idées sous-jacentes sur la violence et la 
constitution des polis en vigueur à ce moment. Le point portant sur les relations entre l'usage de la force, la possibilité du lien social et nature humaine font encore l'objet de discussions au sein de champ académique face à les nouveaux conflits sur la scène politique internationale.

Mots-clés: guerre civile; nature humaine; société; sophistes; stásis; Thucydide.

Resumo. Objetivo deste artigo é contrastar os conceitos de sociedade e da natureza humana na obra de Tucídides, com a doutrina antropológica do grupo de sofistas que foram seus contemporâneos no século $\mathrm{V}$ a.C., tais como Protágoras, Trasímaco, Prodicus, Crítias, e especialmente, Antiphontas, mestre historiador. No entanto, as ideias atribuídas aos representantes deste movimento intelectual serão colocadas sobre os detalhes que o próprio Tucídides extraiu da sua descrição de stásis ou guerra civil na cidade de Corcyra para explicar a invariância do comportamento humano em situaçôes de extrema necessidade. Em seu relato dos fatos, Tucídides destaca a stásis não só como um modelo da Guerra do Peloponeso, mas a eleva a categoria de paradigma universal de toda confrontaçáo bélico-militar. Em última análise, e dependendo de como o caso é tratado pelo autor no livro III, 81-83 em sua História, vemos que essas passagens também são susceptíveis de ser reinterpretada à luz das teorias sofistas sobre os primórdios da civilização, que por sua vez sistematizaram ideias subjacentes sobre a violência e sobre a constituição do polis vigentes nesse momento. A questão da relação entre o uso da força, a possibilidade de laços sociais e da natureza humana ainda é objeto de debate na academia frente aos novos conflitos, dentro da cena política internacional.

Palavras chave: guerra civil; natureza humana; sociedade; sofistas; stásis; Tucídides.

\section{Introducción}

En lo que sigue no se pretende zanjar definitivamente la cuestión referente a la complejidad de la teoría tucidídea sobre la guerra civil y su alcance como modelo universal de todas las guerras ni, en consecuencia, responder por el sentido último de su poder explicativo para toda forma de guerra en general. De cierta manera, esto ya ha sido desarrollado en la notable investigación adelantada por Jonathan J. Price en su libro Thucydides and Internal War (2001). Por el contrario, la pregunta que desarrolla este artículo apunta a precisar cómo la visión de Tucídides sobre el hombre y la guerra pudo tener como referente teórico lo dicho por otros pensadores activos en la segunda mitad del siglo siglo V a. de C. en la Grecia clásica, de cuyas doctrinas de seguro conocía, y qué postura llegó a asumir para distanciarse de aquellos. Esto permitirá establecer mejor su contribución al momento de definir el concepto de naturaleza humana y las implicaciones que ello comporta para entender hoy no solo los conflictos internos activos en el mundo, sino también las dinámicas de "guerra civil ampliada" en el contexto internacional y la estrecha relación que juntos fenómenos guardan entre sí.

En la literatura más reciente han existido varios intentos de relacionar las ideas de Tucídides con los sofistas. Pero en esta la discusión se ha circunscrito sin ambages a una serie de puntos de orientación general o bien los especialistas se han contentado con simples alusiones indirectas al pensamiento filosófico posterior en torno a la digresión tucidídea sobre la guerra civil o stásis. De este modo, dichas aproximaciones presentan dos vertientes principales.

Por un lado, están los enfoques de orden formal y que ponen el acento en los aspectos retóricos o discursivos. Estos subdividen la temática en diferentes tipos de análisis, tales como: i) 
describir semejanzas de índole estilística y terminológica entre Tucídides y algunas doctrinas sobre el lenguaje de la primera sofística (Solmsen, 1971); ii) destacar la célebre oposición naturaleza/ cultura, sin llegar a establecer paralelismos específicos con algún representante de la llamada ilustración griega en particular (Saxonhouse, 1978; Lebow, 2001, pp. 553 y ss.;); iii) mostrar el uso de la dialéctica y sus antecedentes entre los sofistas, tal como aparecen en los discursos cuyo objetivo principal en la obra de Tucídides es presentar las motivaciones que están en el trasfondo de las decisiones políticas asumidas durante el curso de la guerra (de Romilly, 1967/2013, pp. 151-198); iv) postular hipótesis sobre la psicología colectiva presente en la prosa del historiador en forma de reglas de conducta para grupos de personas (ejércitos, audiencias, muchedumbres, o incluso ciudades) y buscar allí la conexión entre Tucídides y las tesis planteadas al respecto sobre el alcance de la persuasión retórica por un sofista como Gorgias (Hunter, 1986); v) intentar una investigación en donde se ponga en paralelo la inversión de los valores morales fundados en la tradición y la simultánea modificación de los usos lingüísticos por obra de los sediciosos mediante la creación de una "retórica partisana", que en Tucídides tendría por modelo no explícito las estrategias ya formuladas en las teorías retóricas enseńadas previamente por los sofistas (Loraux, 2008, pp. 105-133).

Por otro lado, están las perspectivas de contenido histórico, que si bien tienen como eje central el caso de sedición en Corcira (Orwin, 1988; Swain, 1993; Reeve, 1999) no abordan directamente de qué modo, por ejemplo, la transformación en el uso de las palabras, la ruptura de las costumbres y las normas legales o los excesos de violencia, cuyos rasgos son todos descritos por el historiador durante la stásis, son temas que podrían estar relacionados con algunas cuestiones que ya habían sido tratadas por la sofística de su tiempo. Y si hay un intento de comparación en el contexto intelectual, ello se ha limitado al terreno de las filosofías platónica y aristotélica.

Con referencia a Platón, son varios los temas que se toman en consideración: i) el que acentúa la respectiva contribución, el uno como historiador, el otro como filósofo, al actual debate teórico sobre la democracia moderna (Mara, 2001); ii) el relativo al tópico de la utilidad y la justicia que confronta la perspectiva de Tucídides, ofrecida en el "debate de Melos", a la suministrada por Platón, conforme es expuesta por este último en el libro I y II de su República (Vimercati, 2008); iii) el que contrapone en estos dos pensadores la diferencia que es posible trazar entre debate y diálogo a la luz del cuadro general del discurso político (Boyarin, 2012).

En lo tocante a Aristóteles, más allá de adelantar cualquier colación doctrinal, el análisis comparativo se ha efectuado dentro de los márgenes de un desigual tratamiento que hiciera el Estagirita de la guerra civil en obras capitales como la Politica o la Constitución de los Atenienses, con vistas a encontrar la especificidad del modo en que el historiador abordó antes la situación político-militar generada por la stásis y que le sirvió de paradigma para dar cuenta del fenómeno en todas las ciudades griegas durante el transcurso de la Guerra del Peloponeso (Williams, 1985; Zatta, 2011).

Ante este abanico de posibilidades, es preciso señalar la existencia de un aspecto en común entre Tucídides y los sofistas. Dicho aspecto se vincula con el enfoque realista que ellos tuvieron de la función que cumplen las instituciones sociales en la organización de los modos de vida y su subsiguiente crisis al ser puestas en cuestión bajo el peso de las acciones impuestas a los hombres a causa de la guerra, en el orden de los hechos, y luego sometidos a crítica, en el orden histórico-filosófico en sentido estricto. Todos elementos que a su manera o con cierta independencia fueron 
desarrollados por cada autor, si bien guardando — con algunas salvedades - ciertas afinidades y resonancias presentes tanto en la Historia de Tucídides como en las especulaciones que pueden recogerse en los fragmentos que hoy conservamos de los antiguos sofistas o algunas de sus doctrinas ${ }^{1}$. A continuación, se expondrán los lineamientos que se desprenden de tales elementos en relación con el tema de la stásis o guerra civil.

\section{La encrucijada cívica de la "ley del más fuerte"}

En la medida en que, para Tucídides, la naturaleza humana — visible en las acciones de imponerse o resistir - aparece como una constante en el desarrollo de los eventos que caracterizaron el conflicto panhelénico entre Esparta y Atenas (Th., I, 22.4; III, 82.2), la "ley del más fuerte" no solo marcó de este modo la relación entre ciudades-Estado, sino que sirvió también de plataforma a los sofistas para cuestionar las convenciones sociales en el interior de una sociedad, por considerar como innatas las tendencias egoístas mostradas por los individuos al momento de defender sus propios intereses. Unas tendencias por las cuales, según Trasímaco (85 A10 y B6 D.-K.), asimismo se regulaba la dinámica comportamental exhibida por quienes se habían encargado del gobierno en favor de su propia conveniencia (grupo dominante) y por quienes habían de aceptar las medidas que otros tomaran por ellos (grupo dominado) en el contexto de una misma polis. Pero aquí hay una distinción de nivel y una paradoja que se debe tomar en consideración.

En efecto, mientras que por invocación de la "ley del más fuerte" no se puede apelar a cuestiones de derecho, esperanza o justicia divina para las relaciones entre una potencia y sus subordinados, o entre un imperio y los que este desea someter — son las objeciones que hacen los atenienses a los dirigentes de Melos (Th., V, 96-97 y 102-105)_, por el contrario, en las relaciones de los ciudadanos que conforman una única organización política las cuestiones de justicia social y de moralidad pasan a un primer plano. De ahí que Saxonhouse, por ejemplo, haya propuesto separar en la Historia de Tucídides las relaciones "intra-polis", donde priman para una sola comunidad las cuestiones sobre el nómos, de las relaciones "inter-polis", donde se justifica las acciones político-militares en contra de otra comunidad externa en términos de physis, es decir, de legítimo dominio de los más fuertes sobre los más débiles (Saxonhouse, 1978, p. 468)².

1 En adelante, la Historia de la Guerra del Peloponeso de Tucídides es citada por las dos primeras letras del nombre latino del autor (Th.), seguido, en su orden, por el número del libro, el parágrafo y la línea correspondiente a la versión en griego de la $O x f o r d$ Classical Text (Jones, H. S. \& Powell, J. E. [Eds.], 1942). Para las citas de los sofistas y los filósofos presocráticos, la ordenación se ajusta a la establecida por Diels y Kranz (D.-K.), en su edición crítica (1954) que aún hoy se toma como referencia para los fragmentos de estos pensadores. Allí a cada autor le es asignado un número y la correspondiente clasificación de autenticidad del pasaje en cuestión mediante las letras: A, para testimonios; B, para fragmentos posiblemente auténticos; $\mathbf{C}$, para imitaciones hechas por otros autores tardíos. En todos los casos, se recurre a las traducciones castellanas que en años recientes ofrecen una versión fiel del texto original. Estas obras, tanto en sus ediciones críticas como en sus traducciones, han sido incluidas al final en la bibliografía y por convención las referencias son hechas según la fijación seguida en ellas. Los anteriores, así como los demás autores antiguos son asimismo referenciados de acuerdo con las abreviaturas empleadas en el Diccionario Griego-Español (DGE), por su amplia aceptación a nivel internacional. Tales listas pueden encontrarse en internet: http://dge.cchs.csic.es/lst/lst $1 . h t m$

2 Dicha distinción entre los niveles interior y exterior de un conflicto bélico es algo que había sido señalado hace tiempo por Platón. Para el filósofo, toda confrontación con un pueblo extranjero, en donde ambos sean enemigos por naturaleza, se la ha de llamar pólemos, mientras que todo enfrentamiento en el interior de la ciudad, en donde los que luchan son amigos por naturaleza y así la comunidad se ha separado en facciones, se la ha de llamar stásis (Pl. Resp. v, 470c-471b). Para Nicole Loraux, la distinción 
Mediante su esquema, Saxonhouse sostiene que las relaciones intra-polis presentan dos facetas. La primera está reflejada por los vínculos de unión cívica que encontramos en tiempos de paz relativa o bienestar general, de los cuales habían disfrutado los atenienses antes de la guerra, y que Tucídides esboza en el discurso fúnebre de Pericles (Th., II, 37-40). La segunda es la que sigue a la guerra y viene representada por la crisis suscitada a raíz de la peste en la propia Atenas y la guerra civil o stásis en Corcira. Estos dos últimos eventos pueden considerarse como coextensivos el uno al otro, dado que la naturaleza humana en ambos casos se revela de forma semejante por el rechazo de las convenciones sociales. Sin embargo, aquí la guerra civil puede que sea, a ojos de Tucídides, un fenómeno mucho más importante. Pues, si las consecuencias de la peste se vieron agudizadas cuando entró en ruina la moralidad y la legalidad, al haber sido la enfermedad un producto del azar o de la mala fortuna para los atenienses recién empezado el conflicto, en cambio, la stásis que estalló en Corcira puede ser considerada a la vez como la causa y el efecto necesarios e implicados por la guerra más amplia, "inter-polis", que se desarrollaba en todo el mundo griego.

La stásis se presenta como causa de la guerra debido a las incursiones que fueron realizadas por iniciativa de los atenienses en Corcira, en cuya ciudad ya existía un enfrentamiento entre partidos. Estas incursiones constituyeron el detonante, junto con las acciones simultáneas adelantadas por Atenas en Potidea, y que llevaron a los peloponesios en 431 a denunciar la ruptura del Tratado de los Treinta Ańos y a declarar la guerra por miedo a sus intenciones expansionistas como imperio. Pero la stásis también se presenta como efecto de la guerra, puesto que cinco años después de haberse iniciado la confrontación internacional, la sedición se intensificó en Corcira por las mismas razones que llevaron a Atenas a tratar de tenerla al principio en calidad de aliado: las facciones de los demócratas siguieron enfrentándose a los del partido aristocrático y ambos bandos fueron esta vez apoyados según sus tendencias en pleno enfrentamiento por atenienses y peloponesios, respectivamente.

Ahora bien, si la stásis de Corcira pudo servir de modelo a Tucídides no solo al caracterizar la forma en que la violencia altera las condiciones de normalidad mediante luchas internas entre facciones por obtener el poder (y bajo las cuales se conduce la política de una ciudad), sino también por ver en ella, en correspondencia con las ideas de los sofistas, el declive de las convenciones sociales, entonces semejante proceso de demolición de las instituciones tuvo lugar como uno de los síntomas en la búsqueda sin reservas, tan connatural al hombre, de garantizar su bienestar individual en detrimento del interés colectivo, es decir, cuando lo que está en riesgo es la propia vida o la seguridad personal. Y en ello reside la paradoja que se mencionó más arriba. Pues si las

\footnotetext{
platónica se remonta a la Orestía de Esquilo, quien en su obra dibujó "en filigrana, la figura ideal de la polis, guerrera afuera de sus puertas y promotora, dentro de estas, de la paz civil. El exterior pertenece a Atenea, el interior es del resorte de las Erinias, que pueden desatar la discordia o, si se vuelven Euménides, regir la reproducción de la ciudad en el tiempo repetitivo de la sucesión de las generaciones" (Loraux, 2008a, p. 31). De modo que la lucha intestina nace entre los allegados, esto es, la "stásis es la guerra familiar instalada en la ciudad" (p. 33) y el origen de su división. Esta tesis ha sido debatida recientemente por Giorgio Agamben (2017, pp. 15 y ss.). No obstante, los argumentos aducidos por él no pretenden otra cosa que forzar el análisis del problema, al querer encerrar el sentido antropológico y político implicado por la stásis como realidad histórica dentro del concepto schmittiano de "estado de excepción", cuya definición solo cubre una de las caras de la guerra civil: la del ordenamiento jurídico y su legitimidad negativa en cuanto soberanía sin límites, al estar dentro y fuera de la ley, sobre las formas de vida. En contraste con las reflexiones y las implicancias extraídas de la tesis defendida por Loraux, su esfuerzo resulta vano, incluso hasta caer en el sesgo y la tergiversación, no solo al no tener en cuenta la segunda parte del libro de Loraux (2008b), sino también al dejar por completo de lado la literatura más reciente sobre el tema y, en especial, un trabajo de la envergadura y trascendencia como el escrito por Stathis Kalyvas bajo el título de La lógica de la violencia en la guerra civil (2006).
} 
convenciones y las instituciones sociales que están fundadas en las leyes y costumbres de una sociedad sirven para retener dentro de ciertos límites los impulsos egoístas de los individuos, esos pilares del equilibrio social solo descubren su función para un observador objetivo (e incluso para los que padecen los peores males fruto del desorden) cuando la violencia de los individuos que sacan provecho de la situación hace sentir a los demás que tales instituciones han sido puestas en entredicho por medio de la guerra.

Esta paradoja se reveló a los atenienses no solo durante la peste en Atenas, sino también durante el derrocamiento de la democracia en 411 con el establecimiento del régimen de los cuatrocientos y, tiempo después, tras la guerra civil que bañó de sangre a la ciudad en 404, al haber sido capturada un ańo antes la flota ateniense por los espartanos. Como lo sugiere Saxonhouse (1978), la exhortación hecha por Pericles al final de su discurso fúnebre, de que era un gran honor para los ciudadanos morir por el bienestar del Estado, encontró un efecto opuesto en las circunstancias que, bajo la consecución de ese ideal, los llevó a perder tanto el imperio como la unidad interna de la polis, a causa de la propia guerra y su particular espíritu de conquista:

Pericles portrays the dead as having willingly subordinated the private to the public. The highest glory, as Pericles puts it, is to be united with the polis through self-sacrifice. Consequently, little sympathy is shown to the survivors who are encouraged if parents to have more children as a security to the state (II, 44.3), while sons and brothers are to contend with the dead in their own pursuit of glory, i.e., death for the sake of the polis. The paradoxes which fill Thucydides' history are present here: the polis protecting its politeia finds fulfilment for its citizens in the activities of war. And yet it is the war that destroys the nómoi and thereby the unity of the polis. (Saxonhouse, 1978, p. 469)

Por lo demás, la constatación del carácter funcional de las leyes escritas no era una novedad en tiempos de Tucídides. A partir de su teoría antropológica sobre la evolución social, desarrollada en un tratado perdido y que quizá se corresponde con el que aparece en el catálogo de sus obras bajo el rótulo De la constitución social en el principio (teoría que además fue reproducida por Platón en el diálogo del mismo nombre), Protágoras de Abdera afirmaba que las leyes humanas son fruto de una larga, dura y amarga experiencia. Si separamos los elementos míticos presentes en la versión platónica (y que de seguro no empleó el abderita en su exposición, en razón de su agnosticismo), los hombres lograron sobrevivir en un estado salvaje, al mantenerse reunidos solo dentro de pequeños grupos u hordas, por medio de la técnica (80 C1 D.-K. = Pl. Pr. 322b). Ante la regularidad e incertidumbre generadas por los peligros (apenas sus herramientas les servían para hacerse de lo necesario y defenderse de los ataques de los animales), con el tiempo los humanos conformaron ciudades y establecieron en ellas nómoi (80 C1 D.-K. = Pl. Pr. 322c). De la doctrina de Protágoras se deduce que los instintos de supervivencia en el hombre son innatos o atribuibles a su constitución natural, pero las virtudes políticas, en cambio, no. Las leyes sirven como garante artificial de la supervivencia en una sociedad o de instrumento político para evitar los actos de agresión mutua. Los códigos de conducta a lo largo del tiempo fueron perfeccionados en la vida de los colectivos humanos por ensayo y error. Sin las leyes, los individuos se entregarían al cuidado de los intereses propios, lo cual desencadenaría una violencia sin cuartel para conseguirlos a toda costa al asumirlos en cuanto fines inmediatos, pero socavando el fin a largo plazo frente al cual las normas son tan solo un medio, a saber, evitar la autodestrucción de la sociedad. 
Si Trasímaco, como se vio, defendía la tesis de que la justicia es lo que conviene al más fuerte, es porque para la supervivencia del colectivo es inevitable la imposición de unos sobre otros. De cualquier modo, esta máxima era para él algo por completo independiente de cuál fuese el tipo de organización política aplicable en esa imposición.

Cada forma de gobierno establece leyes de acuerdo con su conveniencia: una democracia, leyes democráticas; una tiranía, leyes tiránicas; e igualmente las demás formas de gobierno. Y, una vez que han establecido las leyes, suelen demostrar a sus súbditos que lo justo es lo que les resulta conveniente, y al que transgrede esa conveniencia lo castigan como violador de la ley y reo de injusticia. Esa es, en definitiva [...] mi afirmación de que en todas las ciudades es justo el mismo principio: la conveniencia del gobierno constituido. Este, en último término, es el que detenta el poder, de forma que, si se hace un razonamiento correcto, resulta que en todas partes es justo el mismo principio: la conveniencia del más fuerte. (85 A10 = Pl. Resp., I, 338e-339a)

Lo que es justo depende de la perspectiva de quienes puedan someter a través de la fuerza a los más débiles. Las reglas son mantenidas y aceptadas como tales por los que son dominados hasta que una nueva fuerza se erija y se imponga por la violencia, con lo cual establece un nuevo orden de justicia. Cuando Trasímaco habla de que lo justo "es la conveniencia del gobierno constituido", lo dice en el sentido de que el poder de turno será válido, mientras ejerza temporalmente y pueda mantener hasta cierto punto el monopolio de la fuerza. La stásis es la bisagra entre un estado de cosas a otro, pero dejando siempre abierto en el medio el socavamiento de los valores antes reconocidos hasta la configuración de unos nuevos. En el episodio de Corcira, Tucídides nos estaría sugiriendo entre líneas que estos procesos de cambio en los regímenes de gobierno por medio de la sedición son lentos en tiempos de paz, aunque se ven acelerados cuando una ciudad o polis entra junto con otras en estado de guerra a gran escala.

Por último, junto a una visión utilitaria que tiene como objetivo equiparar lo justo con lo conveniente para aquel que se ha impuesto por la fuerza, se puede encontrar una visión pragmática de la justicia tal como la defendió Antifonte de Ramnunte, compatriota y maestro de Tucídides. En un papiro encontrado a principios del siglo XX, el orador y también sofista manifestaba al respecto:

La justicia consiste en no transgredir las normas legales vigentes en la ciudad de la que se forma parte. En consecuencia, un individuo puede obrar justamente en total acuerdo con sus intereses, si observa las grandes leyes en presencia de testigos. Pero si se encuentra solo y sin testigos, su interés reside en obedecer a la naturaleza. Pues las exigencias de las leyes son accidentales; las de la naturaleza, en cambio, necesarias. (87 B44 I = OP 1364, Fr. A Col. i)

Según Antifonte, está justificado para cada persona violar las leyes establecidas por convención, "en la medida en que lo haga sin conocimiento de aquellos que las han convenido, estando libre de toda vergüienza y castigo", a menos que se lo descubra; pero es más dañino para alguien impedir la satisfacción de sus impulsos naturales, "aun cuando escape al conocimiento de la humanidad entera, no por ello el mal es menor, ni sería mayor en el caso de que todos los hombres fueran testigos" (87 B44 I = OP 1364, Fr. A Col., ii). La oposición entre los dos órdenes alcanza, como lo ha apuntado de Romilly (1997, p. 130), un carácter rigurosamente sistemático bajo la forma 
en que su distinción es ilustrada por Antifonte en la tercera columna del papiro, pasaje en donde habla de cómo las disposiciones legales son contrarias a los arreglos de la naturaleza:

Así, por ejemplo, en el dominio de la vista está codificado por la ley lo que los ojos deben y no deben de ver; a propósito de los oídos, lo que estos deben y no deben de oír; de la lengua, lo que debe y no debe decir; de las manos, lo que deben y no deben de hacer; de los pies, los lugares a donde deben y no deben dirigirse; del espíritu, los objetos que debe y los que no debe desear. Pues bien, en nada son más afines ni más próximos a la naturaleza aquellos fines de los que las leyes apartan a los hombres, que aquellos otros hacia los que los encaminan. El vivir y el morir sí son naturales y el vivir les viene a los hombres de aquello que les resulta útil; el morir, en cambio, de lo que no les es útil. (87 B44 I $=$ OP 1364, Fr. A Col., iii)

Lo que participa de la naturaleza empuja a los hombres a luchar por la supervivencia individual y el disfrute de lo conveniente según las circunstancias. La naturaleza trae consigo asimismo sufrimientos y penas que están relacionadas con el hecho de que, en último término, la muerte para todos es ineluctable, pero "esos límites así definidos son tan naturales como los deseos o los placeres, todos igualmente universales como la sensación o la vida: no se trata de un derecho, menos aún de un modelo" (de Romilly, 1997, p. 131). De seguro esta perspectiva de la naturaleza humana fue seguida muy de cerca y confirmada en negativo por Tucídides, según su descripción en el libro II del nuevo estilo de vida adoptado entre los atenienses y por el cual se entregaron a los placeres más ruines y empezaron en adelante a realizar a la vista de todos lo que antes hacían en secreto, en caso de no haber contraído la peste o de sobrevivir a la enfermedad. Las mortales consecuencias de esto socavaron los fundamentos de bienestar de la polis, a la luz de los cuales habían decidido antes embarcarse en una guerra, perspectiva que se modificó en vista del temor por el contagio y la desolación que los rodeaba (Th., II, 53).

En otro pasaje del papiro, Antifonte aduce asimismo el argumento de que quienes ante los demás hacen concesiones en nombre de la justicia, en cuanto son las normas generalmente aceptadas por convención, reprimiendo sus impulsos naturales, se ven a la postre más perjudicados que aquellos que las violan cuando no tienen testigos o satisfacen en secreto lo que prohíben las leyes de manera expresa (87 B44 I = OP 1364, Fr. A Cols., v-vi). En efecto, si el culpable llega a ser descubierto, la ley trata del mismo modo o con los mismos criterios tanto a aquel que se presume infractor como a su víctima. Incluso el culpable puede argumentar razones para verse eximido del castigo, así como lo hace la víctima para acusarlo, aún a veces en perjuicio de su misma persona. Más adelante Antifonte esgrime una idea adicional que parece contradecir su anterior afirmación de que lo justo es seguir las disposiciones instituidas por todos, a menos que se tenga la oportunidad en privado de violarlas, ya que luego define la justicia como el hecho de no perjudicar a nadie.

Aunque hay lagunas en el papiro, lo que parece decir más bien Antifonte es que no es beneficio para ninguna persona denunciar las injusticias que otros han cometido en secreto. De ahí que "quien tal haga no será justo, si realmente es justo el no cometer injusticia contra nadie, sin haber sufrido personalmente una injusticia” (87 B44 II = OP 1797 Col. i). Tucídides, apartándose de su mentor, supo ver que el uso pragmático de las leyes en tiempos de paz cambia rápidamente en situaciones de riesgo. Pues el hecho de seguir lo establecido por las leyes deja de tener por com- 
pleto validez bajo la condición de satisfacer los propios impulsos naturales de forma privada y sin testigos. Pero si este último inciso de la primera definición de justicia dada por Antifonte pasó de ser una excepción a convertirse en regla en el caso del desorden social y la inmoralidad que se suscitó en Atenas por la peste, la segunda definición del sofista Tucídides parece haberla adscrito al caso de la guerra civil entre los corcirenses bajo la fórmula contraria, que parece estar presupuesta en dicha definición: cometer y padecer injusticias es justo cuando se hace en defensa propia o en lucha por los propios intereses.

En otras palabras, la primera definición rige en tiempos de normalidad social y ella impide injuriar a otros a menos que esto vaya en contra de las propias inclinaciones de goce personal, lo cual es infringir un daño a lo que Antifonte dice que es un arreglo por naturaleza (Guthrie, 1992, p. 118); la segunda, en cambio, es violada durante la stásis, dado que queda cancelado el bien común mientras el enfrentamiento entre facciones tenga al final un ganador y se establezca un pacto entre vencedores y vencidos en donde la regla de "no cometer ni padecer injusticias" sirva de medio y a la vez de vínculo moral para refrenar los impulsos individuales.

A pesar de verse indirectamente influido por las teorías sofísticas sobre la evolución y la justicia humanas, Tucídides consiguió ver que durante la guerra civil se puede invertir la secuencia de pasos que en la teoría de Protágoras, por ejemplo, le había llevado a este a suponer que, en cuanto ellos concretaban una serie de logros culturales, permitían a los hombres salir del estado de naturaleza por vía de la adquisición no natural de las artes políticas. En efecto, a causa de los horrores de la violencia, la guerra civil sumergía a la civilización de nuevo en un estado de naturaleza momentánea (en caso de imponerse una nueva forma de organización social) o definitiva (si los individuos terminaban destruyéndose unos a otros). Ambas opciones están en juego en la descripción que legó el historiador sobre la stásis que estalló entre los corcirenses.

\section{La lógica de la violencia en el desmantelamiento de la polis}

Antes de la descripción en torno a los acontecimientos de violencia y recrudecimiento en las hostilidades que se desencadenaron a raíz de las luchas internas en Corcira, Tucídides ya había dado alguna noticia en el libro I sobre un primer avance en la consolidación allí de un gobierno democrático. Durante las operaciones que dieron paso al conflicto panhelénico, los corintios habían capturado, en la batalla naval de Sibota contra la flota de Corcira y otros trirremes atenienses, aproximadamente doscientos cincuenta prisioneros, a quienes retuvieron por ser los principales de la ciudad "a fin de que al repatriarse ganasen Corcira para su causa" (Th., I, 55.1). Es evidente que, a partir de ese momento, sin la presencia de los representantes de la facción aristocrática, los atenienses lograron consolidar con mayor facilidad una democracia en esta polis, conforme a sus ulteriores planes de expansión hacia el occidente. Transcurridos cincos años de haber iniciado la Guerra del Peloponeso, estos prisioneros regresaron con el apoyo de los corintios, para cambiar la democracia por una oligarquía y poder recobrar para sí la ciudad del dominio de Atenas (Th., III, 70.1). Lo primero que hicieron los recién llegados fue someter a juicio a uno de los líderes del partido popular, un tal Pitias, quien, al salir absuelto de la acusación por querer entregar la ciudad a los atenienses, llevó a su vez a los tribunales a los más ricos de aquellos hombres “acusándolos de 
cortar rodrigones para sus viñas" por pertenecer estos a suelo sagrado. Frente al elevado costo de la multa, los aristócratas se sentaron en los templos como suplicantes y, dado que el consejo estaba influenciado por Pitias para aplicar de todos modos la condena, aquellos se unieron al pueblo y lo mataron (Th., III, 70.3-6).

Nótese que en estos enfrentamientos previos a la stásis, los fines privados de una y otra facción son puestos en la balanza de la justicia convencional sin que se pudiese transgredir las normas vigentes, tanto humanas como divinas — tal como las entendía Antifonte- De esta forma se canalizaban las ansias de poder mostradas por los respectivos dirigentes de los bandos enfrentados, que intentaban obtener a toda costa el mayor peso político, según su conveniencia. Pero el enfrentamiento no se mantuvo durante mucho tiempo dentro de esos límites, ya que el equilibrio institucional fue roto en favor de una de las partes en liza.

En efecto, si los oligarcas antes del asesinato de Pitias se justificaron por adelantar tal acción "persuadiendo al pueblo a tener los mismos amigos y enemigos que los atenienses" (Th., III, 70.6), después anularon dicha decisión aduciendo que Corcira en la presente guerra debía de permanecer como antes, es decir, manteniéndose enteramente neutral (Th., III, 71.1). Y ligado al hecho de mandar en seguida embajadores para explicar a Atenas sobre lo recientemente sucedido, Tucídides mismo agrega que todo ello lo emprendieron "de acuerdo con sus propios intereses" (Th., III, 71.2). Luego, una vez que los oligarcas se hicieron así con el poder, derrotaron al pueblo en combate. Al ser este expulsado de la ciudad y aquellos prestos a ocupar la acrópolis (ya que ese era el lugar donde vivían los ciudadanos más acaudalados), el primero pactó una unión con las personas que eran esclavas prometiéndoles su libertad, mientras que los otros buscaron apoyo en ejércitos mercenarios traídos del extranjero (Th., III, 71.3 y 74). Finalmente, siendo derrotados los oligarcas por el pueblo, fueron hechos prisioneros y destinados a ser puestos a bordo de un grupo de naves atenienses que habían arribado desde Naupacto en apoyo del partido demócrata. Motivo que obligó a un número de cuatrocientos ciudadanos que habían sido apresados a refugiarse de nuevo en los templos, negándose a ser desterrados en las naves y a la vista de que sus propios dirigentes habían escapado. Con la intención de prevenir que aquella facción planeara un nuevo levantamiento, los representantes del pueblo los trasladaron a una isla cercana (Th., III, 75). Tiempo más tarde, el partido demócrata, presa del temor ante un inminente ataque naval contra Corcira a cargo de los peloponesios, y para evitar que estos rescatasen a los desterrados, hizo que a estos los trajeran de la isla otra vez a los templos y se pusieron a entablar "negociaciones con los suplicantes y con los otros oligarcas a fin de salvar la ciudad" (Th., III, 79.1 y 80.1). Esta unión incidental y momentánea fue lo que provocó la ruptura del acuerdo implícito vigente en tiempos de normalidad de "no cometer ni sufrir injusticia", pues la aparente unión desencadenó un ajuste de cuentas. Ello debido a que, al no ser respetado en un comienzo por los oligarcas que en su momento accedieron al poder, fue en cambio seguido por los del partido demócrata cuando, tras capturarlos, respetó su vida y los puso luego en la isla enviándoles provisiones y haciéndolos regresar posteriormente con objeto de reunir fuerzas. Pero, bajo la presión de las actuales circunstancias, los demócratas decidieron tomar venganza sin tener para con los conjurados ningún tipo de consideración.

Tal fue el contexto en el que empezaron a ser desmanteladas en Corcira las tres instituciones fundamentales que soportaban el orden social entre los griegos, a saber, el parentesco (la familia), 
las normas legales (el derecho) y las leyes divinas (la religión), y que guiaron, según Orwin (1988), la secuencia de destrucción que desembocó en los hechos de la guerra civil, interpretación sobre la cual se volverá más adelante. Pero lo que no explica este autor es por qué fueron exactamente estos los puntos clave del análisis tucidídeo con respecto a la crisis social de Corcira. En realidad, esos fueron también los ejes de discusión implicados en las teorías sofísticas sobre la evolución de la sociedad, tal cual llegaron a ser formuladas en la segunda mitad del siglo V. Sin embargo, aquí se recurrirá a la doctrina que más arriba se tomó como modelo: la de Protágoras.

Ya se ha visto cómo Protágoras propuso un esquema racionalista para explicar el acceso del hombre a la cultura. Los hombres, al adquirir un primer nivel técnico destinado exclusivamente al sostenimiento de las necesidades básicas y en razón de mantenerse por largo tiempo aislados en clanes pequeños, buscaban agruparse en asociaciones más grandes para alcanzar una mayor seguridad. Pero dos cosas, según Protágoras, lo impedían: i) su ineficacia para luchar contra otros grupos o para enfrentar a las fieras, "ya que no poseían aún el arte política, de la que la técnica de la guerra es una parte"; y, ii) cuando intentaban formar un único cuerpo político, pues "cada vez que se reunían, cometían injurias unos contra otros, al no poseer el arte de la política, de forma que, dispersándose de nuevo, seguían pereciendo" (80 C1 D.-K. = Pl. Pr., 322b). En la versión platónica del texto, los dioses (Zeus, por intermedio de su mensajero Hermes) intervienen y, temiendo que nuestra especie llegase a desaparecer, tomaron la decisión de otorgar a los hombres aidōs y dikēe, "a fin de que fueran principios ordenadores (kósmoi) de las ciudades (póleōn) y vínculos (desmoi) creadores de amistad (philía)" (Pl. Pr., 322c) $)^{3}$.

Para muchos de los sofistas y presocráticos de la época, los dioses y, por ende, la religión, constituían una invención de la humanidad. Estos o bien representaban, como lo sugirió Demócrito, la personificación de los fenómenos naturales que producían universalmente en los hombres temor (68 A75 D.-K.), aparte de las noticias que nos advierten de la irreligiosidad de Anaxágoras, para quien lo divino no era otra cosa que Nous (pensamiento): un atributo exclusivo del ser humano (59 A1 y 3; B12 D.-K.). O bien, dichas divinidades y su veneración eran el resultado, según lo aducía Pródico, de un sentimiento de gratitud por los dones recibidos en el mundo natural, bienes tales como la agricultura (84 B5 D.-K.). O, en fin, alguien como Critias incluso llegó a afirmar que los dioses no eran más que el garante por el cual eran respetadas las convenciones sociales al infundir, para no transgredirlas, el miedo hacia ellos (88 B25 D.-K.). Esto era lo que entendían los intelectuales griegos en el siglo $\mathrm{V}$ sobre la institución religiosa antes o durante el periodo en el que Tucídides redactaba su Historia.

Volviendo al relato de Protágoras, cuyo tema era el ascenso del hombre del estado de naturaleza al mundo de la cultura, para que los individuos les fuera posible formar ciudades, debieron sancionar y reproducir en la convivencia política o en las relaciones con sus semejantes los principios de aidōs y díkē. En lo que respecta al vocablo griego aidṓs, su sentido es de por sí intraducible a una lengua moderna. Pero varios comentaristas han propuesto que supone la idea

3 En el contexto de los simposios de rango aristocrático, Jenófanes de Colofón ya había visto la necesidad de fundar los lazos entre los amigos que dirigen el gobierno de la ciudad tanto en el respeto a la divinidad como en un proceder justo y equilibrado en las celebraciones, al prohibirles cantar los poemas tradicionales que relatan las batallas de los antiguos titanes y cíclopes o las violentas stáseis entre los inmortales, "en las que nada útil hay; siempre, en cambio, es un bien tener consideración a los dioses" (21 B1, vv. 23 y s.). De ahí que el sentido de la elegía en Jenófanes sea estrictamente político. 
de "reconocimiento pleno de deferencia frente a toda superioridad ajena" o "pudor en cuanto vergüenza del mal moral”, según la propuesta de Untersteiner en su edición crítica de los sofistas, que sigue a este respecto a otros filólogos como Wilamowitz y Levy (Untersteiner, 1967, Fasc. I, p. 104, comm. ad. loc.). Guthrie, en su Historia de la Filosofía Griega, precisa el contenido de aidōs, interpretándolo como "una cualidad moral [...] que viene a ser una combinación de pudor, recato y respeto a los demás y que no está lejos de lo que se entiende hoy por "consciencia»" (Guthrie, 1992, Tom. III, p. 74 y s.). Tales traducciones del concepto son insuficientes, pues parten del supuesto de que los términos morales están cargados por la diferenciación de valores psicológicos individuales, mientras que en griego antiguo estos términos referidos a las costumbres están impregnados de resonancias con otras palabras. Tal cosa es palpable en el propio texto del Protágoras platónico, en donde, así como díkē es el principio rector de las ciudades (póleōn), así también aidōs está en conexión directa con los vínculos (desmoí) creadores de amistad (philía), esto es, en cuanto se presenta como elemento que rige su constitución. Siguiendo esta lógica, el lingüista Émile Benveniste (1983) demostró que, por ejemplo, “en Homero hay una relación constante entre phílos y el concepto de aidós'” y que, por ende, ambos iluminan el campo semántico al que juntos eran aplicados. ¿Cuál era, pues, su dominio de referencia? De hecho, este dominio se extendía desde las relaciones de respeto dentro del grupo familiar hasta los sentimientos de solidaridad y apoyo mutuo que los miembros de una sola comunidad sentían al formar parte de una misma etnia o raza ${ }^{4}$. En todo caso, la significación primera derivada de la relación entre phílos y aidōs, atestigua, según Benveniste, "que las dos nociones eran igualmente institucionales e indican sentimientos propios de los miembros de un grupo reducido” (Benveniste, 1983, p. 219). Por tanto, los vínculos de amistad se dan ante todo en aquellos que unen y atan a los allegados o los más próximos: los amigos (phíloi) son ante todo los parientes.

En cuanto a la idea de dikee, al guardar una conexión estrecha con la configuración de la polis, sería tentador entenderla como un sentido personal de justicia o rectitud presente en el individuo éticamente desarrollado en la ciudad (Untersteiner, 1967, Fasc. I, p. 104; Guthrie, 1992, Tom. III, p. 74). Pero la dikè posee un carácter institucional que en su forma plural (díkai) remite más bien a "las fórmulas de derecho que se transmiten y que el juez se encarga de conservar y aplicar", aspecto que se amplía en los comportamientos privados al seguir los usos habituales o las costumbres acordadas, según el caso (Benveniste, 1983, p. 303). Es preciso aclarar que estos usos no son los que postula la naturaleza, sino los que demanda la ciudad o los actos modelados conforme a "la conveniencia del gobierno constituido" (en el sentido que daba a esta expresión la noción de justicia de Trasímaco). No obstante, tiene razón Solana Dueso (2007) cuando afirma que para Protágoras la díkè viene a cubrir todo el campo semántico que tradicionalmente se asignaba a la

4 Recuérdese los pasajes en donde Tucídides hace explícito que uno de los motivos alegados por los protagonistas de la guerra al momento de pactar alianzas o hacer una defección era decir que los atenienses eran jonios, mientras que los peloponesios eran dorios. Por ejemplo, en el libro III, los embajadores tebanos en contra de los platenses que buscaban ser perdonados por los peloponesios, prometiendo rechazar la alianza con Atenas y pasarse así a su bando, defendían que las tropas de Tebas no tomaron Platea por iniciativa propia, sino que los principales de la ciudad les habrían abierto las puertas, intentando ellos llevar así a la ciudad “a la unión con sus hermanos de raza, sin hacerla enemiga de nadie, sino amigos de todos por igual y en paz" (Th., III, 65.3). En el libro IV, Hermócrates, para justificar la unión de todos los sicilianos ante los planes de Atenas para invadir la isla, recuerda a su auditorio que las cuestiones de raza a los que apelaban los atenienses para apoyar a los calcídeos en contra de los que descendían de los dorios, ocultaban su codicia por la riqueza de la que disfrutaban todas sus ciudades (Th., IV, 61.2-3). 
philía y al aidōs, novedad semántica que permitió al sofista introducir el cambio de mentalidad desde una concepción de amistad de orden familiar y privado a una amistad de carácter político y público, incluso separándolas una de la otra (Solana, 2007, pp. 26 y s). De ahí que, si lo imaginamos haber sido con toda probabilidad un lector de Protágoras, Tucídides haya podido resaltar, en su reconstrucción de los hechos, cómo durante la stásis en Corcira y, por ende, en toda Grecia, las filiaciones de partido llegaron a ser más importantes que los lazos familiares o de parentesco.

Esta observación nos obliga a detenernos en los detalles más importantes relativos a la descripción hecha por el historiador ateniense en el famoso pasaje del libro III, 81-82, para asir mejor la visión desengañada que él mismo transmite a sus lectores de la forma y el orden en que fueron desmantelados en Corcira los tres pilares (arriba sumariamente examinados) que servían de sostén al edificio social en la Época Clásica, a causa de la guerra civil.

Lo primero que ocurrió fueron los asesinatos que los demócratas efectuaron como represalia para vengarse de todos los suplicantes que estaban en el templo de Hera y los que de entre ellos habían aceptado subir a las naves para rechazar el ataque de los peloponesios y su flota. Estos últimos fueron asesinados apenas tocaron puerto y tras persuadir a otros cincuenta de los que se encontraban en el recinto para que se sometieran a juicio, también a ellos los condenaron a muerte. Los demás, al percatarse de lo que estaba sucediendo, se dieron muerte a sí mismos como podían (Th., III, 81.2-3). Ante el silencio de los comentaristas recientes sobre este pasaje, la fórmula que se aplica aquí es bastante sencilla: para un nuevo gobierno o su consolidación definitiva, hay que tomar medidas extremas. Lo cual remite a la naturaleza del castigo bajo el marco de la ley para los insubordinados. Existen dos opciones: el castigo puede infringirse para satisfacer la ofensa presente o para evitar que otros repitan la misma falta en el futuro. La osadía para cometer el delito puede darse en la pobreza o estar motivada por la codicia de quienes ya tienen más de lo suficiente para vivir. Esta es una teoría que el propio Tucídides pone en boca de Diódoto para tratar el caso de la irrupción de Mitilene, en donde expresamente hace alusión a la participación en ello de la naturaleza humana:

La naturaleza ha dispuesto que todo el mundo, tanto a nivel particular como público, cometa errores, y no hay ley capaz de impedirlo, puesto que los hombres ya han recorrido toda la escala de penas agravándolas progresivamente, por ver si sufrían menos daños de parte de los malhechores. Y es probable que en los tiempos antiguos las penas establecidas para los delitos más graves fueran más suaves, pero al seguir habiendo transgresiones, con el tiempo, la mayor parte de las penas acabaron en la de muerte; y aún con ellas las transgresiones continúan. Hay que encontrar, por tanto, algún motivo de miedo más terrible que este, o admitir que este, al menos, no supone ningún obstáculo, sino que la pobreza, que azuzada por la necesidad inspira la audacia, la riqueza, que con la desmesura y el orgullo engendra la ambición, y las otras situaciones de la vida sujetas a las pasiones humanas, en la medida en que están dominadas en cada caso por un impulso superior e irresistible, arrastran al hombre hacia los peligros. (Th., III, 44.3-4)

Aquí parece estar implícita una concepción evolutiva de lo social, pero centrada en el tópico de la historia de la pena de muerte. La progresión de lo más antiguo a lo más reciente está marcada por una serie de adquisiciones que se basan en los logros de una larga experiencia colectiva y que es visible en las disposiciones de las normas actualmente en uso. La crueldad para el castigo de las penas llegó al punto de ir agravándose más y más para evitar los daños producidos por otros. 
Pero es imposible contener los instintos naturales de los seres humanos que desean transgredir la ley en aras de satisfacer sus deseos o sacar el mayor provecho cuando tienen la esperanza de poder conseguir lo que pretenden en beneficio propio. Este es un tipo de normatividad que parece estar asociado al principio de "justa retribución", pues si los castigos se hacen más severos, tal cosa es proyectada así para responder a la magnitud de las faltas. La muerte no es más que el símbolo que compendia el sentido último de la compensación. En lo tocante a la osadía y la diferencia que en ello juega la disposición material de recursos o su carencia, esto forma parte de los móviles de quienes cometen las faltas, pero idénticos móviles pueden atribuirse a quienes desean infligir un castigo. Sobre todo cuando se recurre a la justicia para dar muerte incluso de forma injusta, tal como lo hicieron los demócratas corcirenses con los suplicantes resguardados en el templo y que luego empujó a sus partidarios a responder también con la misma moneda.

Es oportuno recordar aquí la observación aportada por Reeve (1999, pp. 437 y s.) de que, en el caso de las stásis en Corcira, fueron los excesos de los oligarcas ricos que estuvieron en el poder lo que los llevó a ser objeto de venganzas por obra de los más pobres cuando estos hicieron que la ciudad retornara a un gobierno democrático, tras el breve intento fallido de los aristócratas para colocarse al frente de la ciudad. Ello suscitó, entre los que eran débiles por la carencia de recursos, de un lado, la codicia (pleonexía) por las posesiones de los que antes eran fuertes debido a su estatus y condición social, $y$, de otro, el desenfreno de ambos grupos exhibido en su intemperancia (orge $\bar{e})$ para irse lanza en ristre contra las leyes humanas y divinas en aras de saciar su sed de venganza (Th., III, 84.1-2).

La sevicia se apoderó de todos, y tras dar comienzo a los primeros crímenes sangrientos, la violencia ya no pudo detenerse. Una vez asesinada la primera víctima, su sangre empieza a arrastrar consigo a toda la comunidad hacia la violencia recíproca. Las costumbres y luego el derecho no son otra cosa sino mecanismos que durante milenios han desviado la violencia interna hacia el exterior (en la imagen del enemigo o el bárbaro) con objeto de evitar la destrucción de la sociedad desde el interior (refrenando los impulsos de agresión sobre los amigos, los allegados, los padres, los hijos). Sin embargo, la religión en el mundo antiguo siempre tuvo aquí un papel muy importante. En efecto, tal como lo planteaba el sofista Critias (88 B25 D.-K., vv. 9 y ss.), si las leyes impedían, por su fuerza, cometer crímenes manifiestos, la invención de los dioses impedía a su vez cometer esos mismos crímenes de manera oculta, argumento con el que uno podría responder a la primera definición de justicia de Antifonte (B 44 I D.-K. = Fr. A Col. i) y asimismo a las dudas de Diódoto de que si existiese otro motivo de miedo aparte de los castigos estipulados por la ley, de cualquier forma este es poco efectivo.

Sea como fuere, el hecho es que una vez lo religioso queda arruinado por la violencia, el edificio social se desploma hasta sus cimientos. René Girard (1995) supo ver la lógica de esta destrucción de lo sagrado y que se corresponde bien con lo que Tucídides dice acerca de lo religioso, a saber, que en circunstancias normales constituye el soporte que hace posible que la venganza no se prefiera "a la observancia de las leyes sagradas" (Th., III, 84.2). Las siguientes palabras de Girard incluso nos parecen una nota a pie de página de lo dicho por el historiador ateniense sobre las secuelas dejadas por la stásis en el libro III, 81.4-5: 
Cuando se descompone lo religioso, no es únicamente, o inmediatamente, la seguridad física lo que se ve amenazado, es el propio orden cultural. Las instituciones pierden su vitalidad; el armazón de la sociedad se hunde y se disuelve; lenta al comienzo, la erosión de todos los valores se precipita; la totalidad de toda la cultura amenaza con hundirse y se hunde un día u otro como un castillo de naipes. Si la violencia inicialmente oculta de la crisis sacrificial destruye las diferencias, esta destrucción a su vez hace progresar la violencia. No se puede tocar el sacrificio sin amenazar los principios fundamentales de que dependen el equilibrio y la armonía de la comunidad. [...] El orden, la paz y la fecundidad reposan en unas diferencias culturales. No son las diferencias sino su pérdida lo que provoca la insana rivalidad, la lucha a muerte entre los hombres de una misma familia o de una misma sociedad (Girard, 1995, pp. 56 y s.).

La crisis sacrificial hace alusión a la confusión que en el paroxismo de las agresiones impide que los hombres distingan entre la violencia pura, o según lo estipulado por las leyes sagradas, y la violencia impura, esto es, los asesinatos entre consanguíneos 5 . Al final del libro III, 81.5, Tucídides nos habla de cómo los suplicantes fueron muertos en las afueras de los templos y emparedados en estos recintos, lo que nos remite a las formas de venganza pública aplicadas por los griegos mediante "la institución de la piedra". En la Grecia Antigua, la lapidación, como lo ha demostrado Eva Cantarella (1996), era puramente ritual y tenía una función que es señalada explícitamente en los textos antiguos por ser de carácter expiatorio, al tiempo que se recurría a ella para ejecutar oficialmente a los culpables implicados en los crímenes por asesinato, conforme al principio de justa retribución (Cantarella, 1996, pp. 68-84). No obstante, en situaciones de necesidad extrema o inminente peligro, los hombres hacen tabula rasa de los valores que los mantienen unidos en situaciones de estabilidad y que les permiten definir quién merece ser castigado y quién absuelto. En efecto, durante la stásis de Corcira las cuestiones de interés personal se antepusieron a los usos reconocidos de la díkè e impulsaron a muchos a emprender acciones para eliminar radicalmente a los que pasaban por ser ahora sus enemigos. Y sin darse cuenta, resultaron atacando incluso a los allegados sin ningún tipo de respeto hacia ellos: la violencia primera es la que se vuelca sobre la propia sangre. En este sentido, es posible entender las palabras de Tucídides cuando alude a la violencia que deja de ser sacra y se difunde rápidamente en todas las direcciones sin hacer distinción entre culpables e inocentes.

Durante siete días [...] los corcireos asesinaron a aquellos de sus conciudadanos a los que consideraban enemigos; el cargo que les imputaban era de querer derrocar la democracia, pero también hubo quienes murieron víctimas de enemistades particulares, y otros, a causa del dinero que se les debía, perecieron a manos de sus deudores. La muerte se presentó en todas sus formas y, como suele ocurrir en tales circunstancias, no hubo exceso que no se cometiera y se llegó más allá todavía. Los

5 No obstante, en contra de Girard, hay que decir que es la stásis, como paradigma de guerra, la única situación extrema que produce el declive de lo religioso, generando actos violentos que fracturan el orden civil y los lazos comunitarios, y no lo que él designara durante mucho tiempo en términos de "crisis sacrificial". Solo después de su último estudio sobre Clausewitz (2007, pp. 21 y ss.), Girard pudo entender — algo tarde y de modo indirecto - la verdadera naturaleza del problema. Incluso podría lanzarse la hipótesis de que en el núcleo de la "maravillosa trinidad" clausewitziana reside la destructora y a la vez creadora potencia de la stásis. Aquí Tucídides se impone histórica y teóricamente sobre el pensamiento del General prusiano. Acerca de la trinidad propuesta por Clausewitz en De la Guerra, véase las lecturas ofrecidas por Andreas Herberg-Rothe (2009, pp. 204-219) y Philippe Dufort (2017, pp. 133-145). La misma división tripartita, pero en contra de la gestación y en pro de la extirpación de la guerra en la ciudad para el ascenso de la justicia, ya había sido teorizada por Platón en los tres primeros libros de la República. Al respecto, véase mi artículo publicado hace algunos años en esta misma revista (Martín, 2011). 
padres mataron a sus hijos, los suplicantes fueron arrancados de los templos y asesinados en sus inmediaciones, e incluso hubo algunos que fueron emparedados en el templo de Dioniso y murieron allí. (Th., III, 81)

Orwin (1988, p. 836) ha propuesto que a partir del libro III, 82 6-7, Tucídides habla de la forma que adopta siempre la naturaleza humana presionada por la guerra, mientras que "en tiempos de paz y prosperidad tanto las ciudades como los particulares tienen una mejor disposición de ánimo porque no se ven abocados a situaciones de imperiosa necesidad” Th., III, 82.1-2). Al sugerir antes de qué modo este estado de cosas se difundió por toda la Hélade (Th., 82.3) y dio pie al cambio en el uso de las palabras y las formas de valoración (Th., 82.4-5), él procede luego a enumerar una especie de orden en el colapso de las tres instituciones fundamentales en la sociedad griega: el parentesco, las leyes humanas y las leyes divinas, de las cuales ya se ha tratado.

Dicha secuencia de destrucción suscitó la ruina de la sociedad durante el proceso que fue gestado por un conflicto civil interno. Es pertinente resaltar la forma en que la decadencia del marco legal y religioso provocó en Corcira una erosión del ideal del bien común, acción que se debe considerar como primer síntoma de la stásis, ya que fue el punto de quiebre para el desmontaje del edificio social asentado en los tres pilares que sostienen su estructura. Pero en vez de atribuir al bien común un valor trascendente, en su hundimiento Tucídides descubriría una cualidad funcional de las normas en cuanto son instrumentos útiles para mantener la prosecución de los intereses privados dentro de ciertos límites aceptables, pero que solo aparece como una cualidad tal justo en el momento en que las normas no son respetadas mediante las acciones violentas de aquellos que las transgredieron abiertamente.

\section{Conclusión}

Según Tucídides existen casos excepcionales en donde queda revelada una parte de la naturaleza humana. Como lo ha sugerido Reeve (1999, pp. 438 y 442 y ss.), la otra parte estaría representada por la prudencia que es exhibida en tiempos de paz y que nuestro historiador identificaría en las actitudes de personajes históricos como Pericles e incluso Nicias en la esfera política. Sin embargo, la violencia y las formas de agresión parecerían ser constantes en su radicalidad tanto en estado de guerra frente a un enemigo externo como una vez alcanzado su máximo grado, dentro del espacio de la ciudad, bajo la forma de una guerra civil.

Dichas tendencias suponen en la obra de Tucídides y en el episodio de Corcira, en particular, dos tipos de contexto social diferentes e incluso contrapuestos. De un lado, los esquemas de comportamiento básico se mostrarían en su estado natural en situaciones de peligro y necesidad extrema. De otro, están los sentimientos de confianza colectiva e individual (alimentados por pasiones como la ambición o la esperanza) que, al apoyarse en el propio poder de que se disponga para reducir o derrotar a los otros, sirven de modelo para tratar de ampliar y proyectar en el futuro el propio bienestar en caso de que alguien logre imponer sus objetivos por la fuerza. Las luchas entre facciones siempre parten de semejante presupuesto. Si consideramos ambos casos, la naturaleza humana no sería para Tucídides, como sí lo fue en cierta medida para todo el movimiento sofísti- 
co, el hacer tabula rasa de las costumbres desde un punto de vista meramente intelectual. En caso de existir la posibilidad de barrer por completo con las instituciones actualmente vigentes, ella solo se produce por causa de la violencia o por el propio empuje de satisfacer las necesidades individuales.

De ahí que la humanae naturae (y esta es la deuda que Tucídides tuvo con los sofistas) responda, en el marco de los acontecimientos históricos, a una especie de impulso de agresión contra el otro, cuyo objetivo último sería la imposición del más fuerte sobre el más débil, así como la posibilidad de que se dé lo contrario, esto es, la defensa casi instintiva de este último contra aquel (Almandós, 1992, p. 74). Pero también ella es vista por nuestro historiador como una réplica a una sensación de insatisfacción siempre latente y que los hombres no han dejado de expresar en forma de rechazo ante cualquier género de vida que lleven colectiva o individualmente. En todo caso, al momento de entrar los individuos y la comunidad en contacto con la violencia, la guerra y la stásis en conjunto desencadenan una nueva serie de efectos:

a. Se suspende o se suprime cualquier criterio de juicio o de valoración ética o moral. Los impulsos agresores y las razones aducidas para la insatisfacción acaban destruyendo el modus vivendi. Al dar inicio a la destrucción de las instituciones sociales vigentes, no solo se pone en evidencia su contingencia histórica, sino que la propia variabilidad cultural de las convenciones o normas a lo largo del tiempo por las que ellas se regulan las hacen vanas y susceptibles de modificación, según lo conveniente en cada caso.

b. Lo que vale en la naturaleza humana, una vez abolidas las instituciones y las costumbres por vía de la violencia, es su capacidad de hacerse con unas nuevas, conforme lo demande la situación.

c. La supresión del orden social y la relatividad de las normas morales o su inversión conllevan el agnosticismo religioso. Para Tucídides, la Guerra como maestro de violencia, nos enseñaría a todos que la creencia en los dioses consiste en una mera opinión, mientras que los asuntos de los hombres, en cambio, sí son una certeza y a la vez el fundamento de toda ontología política.

\section{Referencias}

1. AA.VV. (2000). Los filósofos presocráticos (3 Vols.; Trad., Introd. y notas C. Eggers Lan et. al.). Madrid: Editorial Gredos.

2. AA.VV. (1997). Sofistas. Testimonios y fragmentos (trad., introd. y notas A. Melero Bellido). Madrid: Editorial Gredos.

3. Agamben, G. (2017). Stasis. La guerra civil como paradigma político. Homo sacer, II, 2 (Trad. R. Molina-Zavalía; Rev. F. Acosta). Buenos Aires: Adriana Hidalgo Editora.

4. Almandós, L. (1992). Naturaleza humana y causas de la guerra en Tucídides. Texto y Contexto, 19, 63-76.

5. Benveniste, É. (1983). Vocabulario de las instituciones indoeuropeas (Trad. M. Armiño; Rev. J. Siles,). Madrid: Ediciones Taurus.
6. Boyarin, D. (2012). Deadly Dialogue: Thucydides with Plato. Representations, 117 (1), 59-85.

7. Cantarella, E. (1996). Los suplicios capitales en Grecia y Roma. Orígenes y funciones de la pena de muerte en la antigüedad clásica (Trad. M.-P. Bouysspon Cheval). Madrid: Ediciones Akal.

8. Diels, H., \& Kranz, W. [Eds.] (1954). Die Fragmente der Vorsokratiker (3 Vols). Berlin: Weidmannsche.

9. de Romilly, J. (1997). Los grandes sofistas en la Atenas de Pericles (Trad. P. Giralt Gorina). Barcelona: Editorial Seix Barral.

10. de Romilly, J. (1967/2013). Tucídides. Historia y razón (Trad. J. Terré Alonso). Madrid: Editorial Gredos. 
11. Duffort, P. (2017). Clausewitz y sociedad. Una introducción biográfica a las lecturas neo-clausewitzianas (Posfacio y Coord. J. A. Ruiz Mora; Trad. H. Martín Alvarado). Bogotá: Sello Editorial Esmic / Université Saint-Paul.

12. Girard, R. (1995). La violencia y lo sagrado (Trad. J. Jordá). Barcelona: Editorial Anagrama.

13. Girard, R. (2010). Clausewitz en los extremos. Politica, guerra y apocalipsis: conversaciones con Benoit Chantre (Trad. L Padilla López). Buenos Aires: Katz Editores.

14. Guthrie, W. K. C. (1992). Historia de la filosofía griega, Tom. III. Siglo V. Ilustración (Trads. A. Medina González et. al.). Madrid: Editorial Gredos.

15. Herberg-Rothe, A. (2009). Clausewitz's "Wondrous Trinity" as a Coordinate System of War and Violent Conflict. IJCV, 3 (2), 204-219.

16. Hunter, V. (1986). Thucydides, Gorgias, and Mass Psychology. Hermes, 114. Bd., H. 4 (4th Qtr.), pp. 412-429.

17. Jones, H. S. \& Powell, J. E. [Eds.] (1942). Thucydides Historiae. Oxonii: E Typographeo Clarendoniano.

18. Kalyvas, S. (2010). La lógica de la violencia en la guerra civil. (Trad. P. Monroy). Madrid: Ediciones Akal.

19. Lebow, R. N. (2001). Thucydides the Constructivist. The American Political Science Review, 95 (3), 547-560.

20. Loraux, N. (2008a). La ciudad dividida. El olvido en la memoria de Atenas (Trad. S. Vassallo,). Buenos Aires: Katz Editores.

21. Loraux, N. (2008b). La guerra civil en Atenas. La politica entre la sombra y la utopía. (Trad. A. Iriarte). Madrid: Ediciones Akal.

22. Mara, G. M. (2001). Thucydides and Plato on Democracy and Trust. The Journal of Politics, 63 (3), 820-845.

23. Martín Alvarado, H. (2011). Filósofos, guerreros y artesanos. El uso de la ideología trifuncional indo-europea en la
República de Platón. Rev. Cient. Gen. José Maria Córdova, 9 (9), 359-383.

24. Price, J. (2001). Thucydides and Internal War. Cambridge: Cambridge University Press.

25. Orwin, C. (1988). Stasis and Plague: Thucydides on the Dissolution of Society. The Journal of Politics, 50 (4), 831-847.

26. Reeve, C. D. C. (1999). Thucydides on Human Nature. Political Theory, 27 (4), 435-446.

27. Saxonhouse, A. (1978). Nature \& Convention in Thucydides' History. Polity, 10 (4), 461-487.

28. Solana Dueso, J. (2007). Philía entre Eros y Díke. Convivium. Revista de Filosofía, 20, 23-36.

29. Solmsen, F. (1971). Thucydides' Treatment of Words and Concepts. Hermes, 99. Bd., H. 4, pp. 385-408.

30. Swain, S. (1993). Thucydides 1.22.1 and 3.82.4. Mnemosyne, Fourth Series, 46 (1), 33-45.

31. Tucídides (1992). Historia de la guerra del Peloponeso (Trad., introd. y notas J. J. Torres Esbarranch). Madrid: Editorial Gredos.

32. Untersteiner, M. (1967). Sofisti. Testimonianze e frammenti (4 Fasc). Firenze: La Nuova Italia Editrice.

33. Vimercati, E. (2008). La legge del più forte. Il dibattito su utilità e giustizia in Tucidide V, 84-116 e Platone, Repubblica I-II: Un confronto. Rivista di Filosofia Neoscolastica, 100, 463-503.

34. Williams, M. F. (1985). Two Traditional Elements in Thucydides' Corcyrean Excursus. The Classical World, 79 (1), 1-3.

35. Zatta, C. (2011). Conflict, People, and City-Space: Some Exempla from Thucydides' History. Classical Antiquity, 30 (2), 318-350. 